\title{
LA-5303-MS
}

INFORMAL REPORT

An Apparatus for the Reduction of Tritium Emissions into the Atmosphere 
In the interest of prompt distribution, this LAMS repor was not edited by the Technical Information staff.

Printed in the United States of America. Available from

National Technical Information Service

U. S. Department of Commerce

5285 Port Royal Road

Springfield, Virginia $2215 i$

Price: Printed Copy $\$ 3.09$; Microfiche $\$ 0.95$

$$
\text { 4.00 }
$$




\section{An Apparatus for the Reduction of Tritium Emissions into the Atmosphere}

by

C. M. Dube*

D. O. Coffin

R. D. Stoil

"Present Address: Rice University, Houston, Texas

This report was prepared a

sponsored by prepared as an account of work sponsored by the United States Government. Neither the United States nor the United States Atomic Energy Cominission, nor any of their employees, nor any of their contractors, subcontractors, or their employees, makes any warranty, express or implied, or assumes any legal liability or responsibility for the accuracy, complekeness or usefulness of any information, apparatus, product or process disclosed, or represents that its use would not infinge privately owned rights. 
AN APPARATUS FOR THE REDUCTION OF TRITIUM

EMTSSIONS INTO THE ATMOSPHERE

by

C. M. Dube

D. 0. Coffin

R. D. Stoll

\section{ABSTRACT}

A method 18 described for the removal of trittum from exhaust gases. The equipment and techniques are presented for the conversion of tritium to tritium water using a catalytic converter and the subsequent capture of the tritfun water on molecular sieves. The test gas contagined $0.5 \%$ tritium, and using flow rates between $100 \mathrm{~cm} / \mathrm{min}$ and $500 \mathrm{~cm}^{3} / \mathrm{mln}$, a reduction occurred in the amount of tritium in the exhaust gas by a factor of over 250,000 .

\section{INTRODUCTION}

An Enviromental Control System (henceforth called ECS), 1s here described which processes "waste" gas evacuated from a primary spotem and reduces the emission of radioactive tritium into the atmosphere. The "waste" gas 18 a mixture of a1r, tritium, deuterium, and helium- 3 of varying proportions. The basic chemical process is as follows. The gas is mixed with air and then forced through a catisytic converter which combines the oxygen in the alr with the hydrogen lsotopes to form water (heavy water and tritium water). The mixture then flows through a molecular steve which adsorbs the water. The remaining gas 18 released Into the atmosphere.

\section{MECHANICAL DESIGN}

A schematic of the aystem 18 presented in Fig. 1. Gas is pumped into a holding tank from the primary agstem. Valve vo la controlled by the primary system. The BCS may be started either when the holdIng tank pressure reaches a preset value (approximately $15 \mathrm{ps} 1 \mathrm{~g}$ ), or by a r.1me swltch, or manually. The gas is pumped from the holding tank by a bellows pump through a pressure regulator set at $1 \mathrm{psig}$

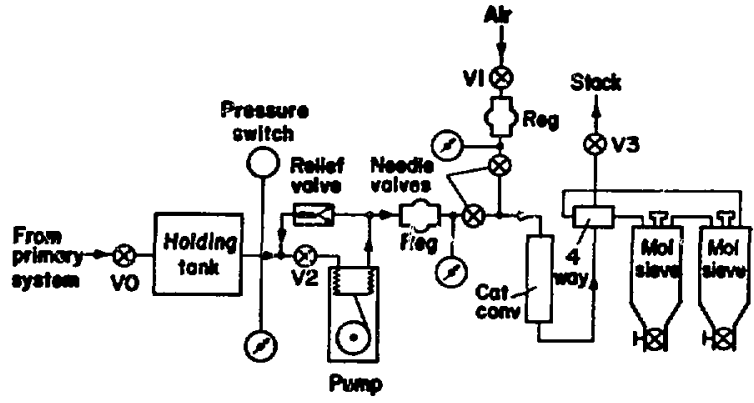

F1g. 1. System schemat1c.

and a micrometer needle valve. The pump has a maxImum allowable output pressure of 25 paig; therefore a relief valve set te 10 psi differential is provided to bleed excess gas back Into the holding tank.

A1r is infected into the system by an Identical pressure regulato: and needle valve arrangement as shown in F1g. 1. The two gas streams $\mathrm{mix}$ and flow at a low rate through the catalytic converter where the hydrogen 1eotopes combine with oxygen to form water. The vapor mixture 18 then directed sequentially by a 4-way valve through two contalners filled with molecular bleve materfal, where the water 


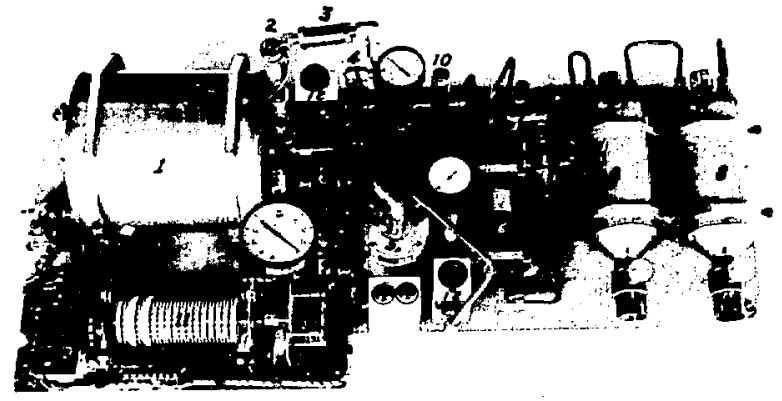

FIg. 2. Environmental Control System.

1. holding tank

2. Pressure swltch

3. Rellef valve

4. A1r supply

5. Bellows pump

6. Catalytic converter.

7. 4-way valve

8. Molecular sieve containers

9. Solenold valves

10. Needle valves

11. Programmer

12. Pressure regulator

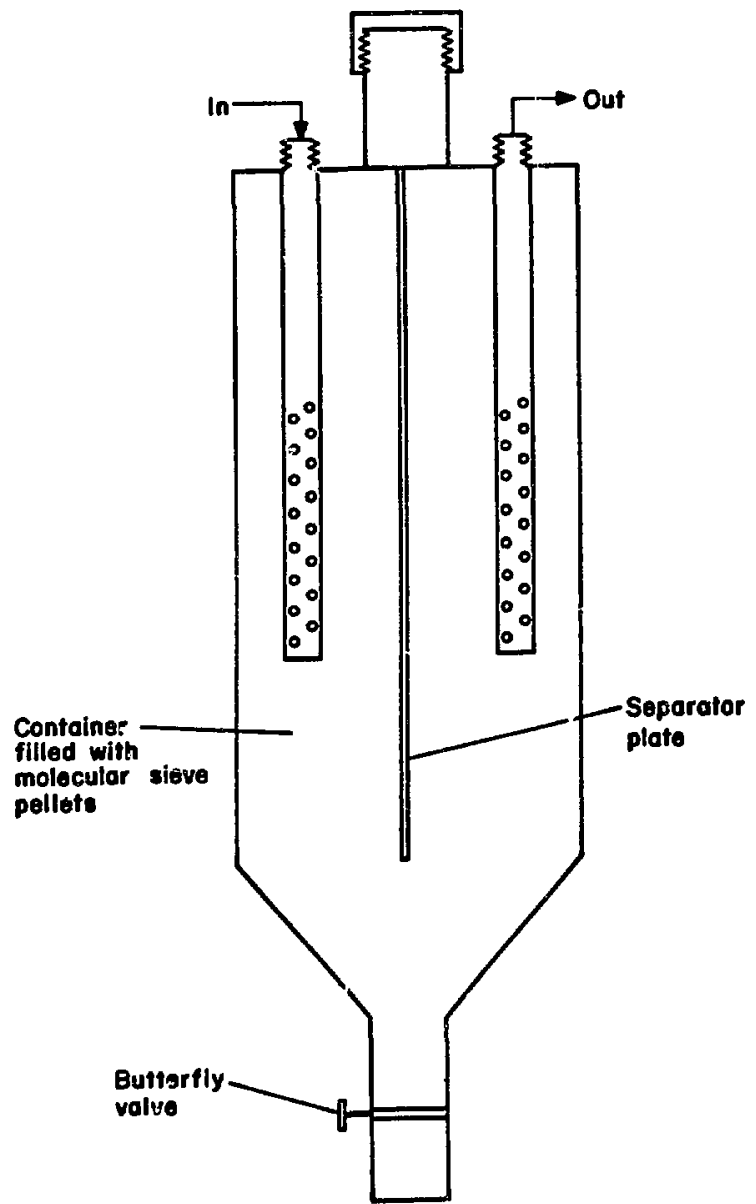

F1g. 3. Molecular sleve container.

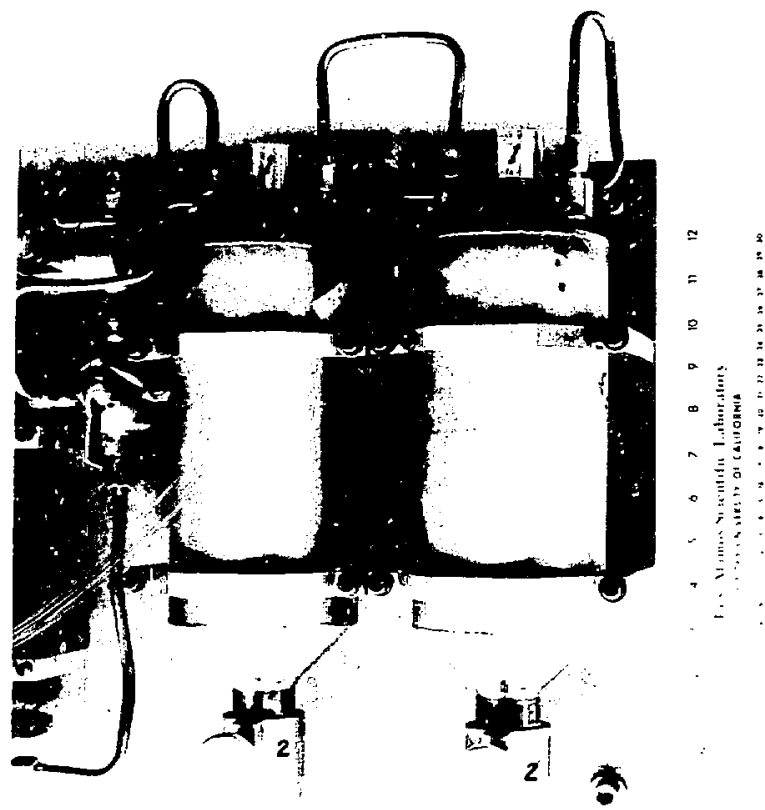

F1g. 4. Molecular sieve containers.

1. Filling cap

2. Butterfly valve

is removed. The remalning dry gas passes back through the 4-way valve and out a stack. Process1ng stops when the pressure in the holding tank is reduced to a value preset on the pressure switch. The proposed mounting location made it necessary to make the systen as compact as possible. General dimensions are indicated in Fig. 2. The two molecular sleve containers have butterfly valves mounted on funnelled bases so the contaminated sieve pellets (Linde Molecular Sieve - Type 13X) can be drained perlodically and replaced. Figures $3 \& 4$ 1llustrate the basic sleve container des.gn. Soft copper tubing and flare fittings are used throughout.

III. CONTROL AND ELECTRICAL SYSTEM

The ECS is controlled by a stepping switch programmer (see Fig. 5). The programuer is basically a drum made up of disks which rotate as a single unit through 24 positions. Pegs which fit on the rim of a disk actuate a lever-operated switch when the disk is roated to the proper position. The programmer is provided with connections to Induce single 


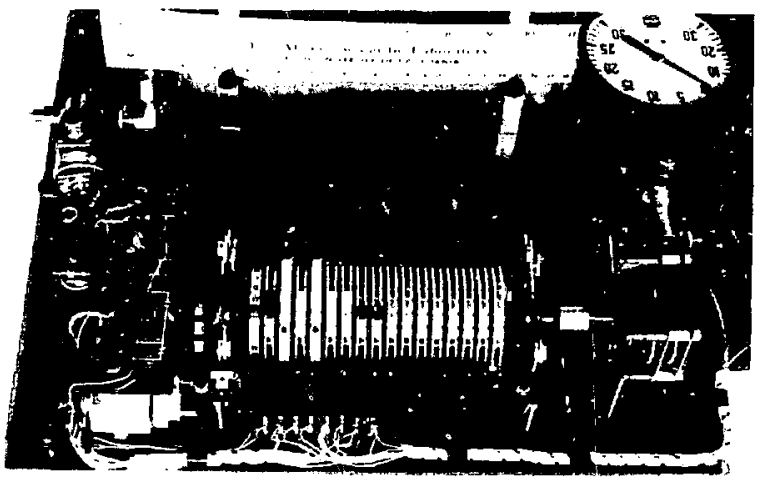

Fig. 5. Stepping switch programer.

or continuous stepping of the drum. The programmer Is programmed fur sequential operations by the appropriate placement of pegs and accompanying signal circuitry through the lever switches. The sequence of operations for a time switch inttlated cycle is as follows. (Refer to Figs, 6 and 7.) When the time switch closes the. programmer advances one step. The solenoid valves V1, V2, and V3 open (see FIg. 1), the pump starts, and the pressure switch circult is partially completed. The processing of the gas then proceeds. When the holding tank pressure drops to a prescribed value, the pressure switch closes causing the programer to single step.

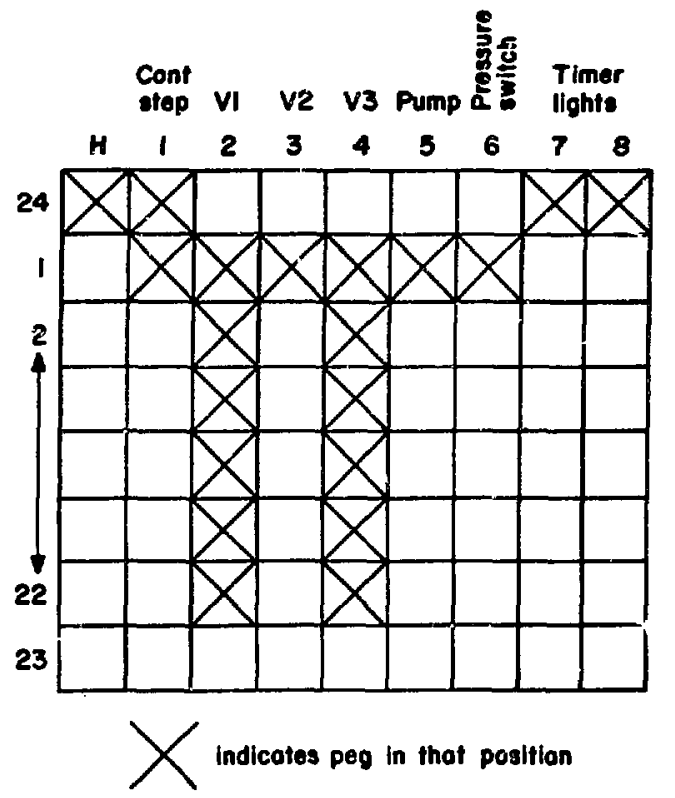

Fig. 6. Drum program chart.

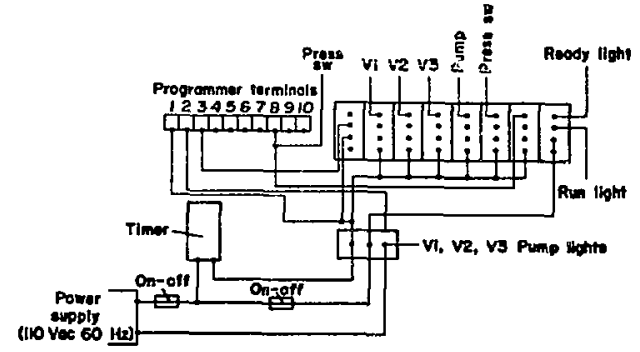

Fig. 7. ECS electrical zystem schematic.

Valves V1, V2, and V3 close and the pamp stops. A circuit through lever switch \#1 is completed to the continuous stepping input. The drum rotates unt1l at position 24 the continuous stepping circuit is broken, placing the programmer in the ready position for a new cycle. Signal lights connected through lever switch $\# 8$ iridicate whether the system is in the "READY" or "RUN" mode.

Because the system is automatically controlled, it can be operated during off hours. However, since operation of the system may be unsupervised and because of the hazardous nature oi tritium, an abort feature has been included in case of pump or power fallure. Should pump performance drop resulting in insufficient vacuum to operate the pressure switch, a time switch cuts power to the system after a certain perlod. This causes the pump to stop and all valves to clcse. The "RWN" light remains on, Indicating a malfunction to personnel upon return. The same thing happens in the event of a temporary power fallure. A manual ON-OFF switch is also included in the circuitry. All power is drawn from a standard $120 \mathrm{VAC}-60 \mathrm{~Hz}$ supply.

\section{TEST PROGRAM}

The output of the ECS was fed directly into a Kanne chamber at known flow conditions to yield a quantitative measure of the extremely low tritium concentration. The kanne chamber is a very sensttive Ionization chamber used to monttor gaseous radioactive B-emitting contaminants. A mass spectrographic analysis of the test gas, before processing, showed Its composition to be: 


$\begin{array}{rr}\mathrm{T}_{2} & 0.47 \% \\ \mathrm{D}_{2} & 41.65 \% \\ \mathrm{H}_{2} & 0.33 \% \\ 3_{\mathrm{He}} & 0.32 \% \\ \mathrm{~N}_{2} & 47.33 \% \\ \mathrm{O}_{2} & 9.90 \%\end{array}$

The test procedure was as follows. Gas was pumped Into the holdiag tank from a larg" reservoir through valve vo. The valve was then closed and the ECS started manually. The gas was pumped from the holding tank at approximately $80 \mathrm{~cm}^{3} / \mathrm{min}$ (STP). The output signal from the Kanne chamber was recorded on a chart recorder. The total amount of $T_{2}$ escaping from the ECS may be determined by integrating the amp vs time curves. The calculation is:

$$
\mathrm{cm}^{3} \text { of } \mathrm{T}_{2} \text { out }=\frac{\mathrm{A} \times 2.3 \times 10^{7}}{2.6 \times 10^{6} \frac{\mu \mathrm{Cm}-\mathrm{amp} \times \mathrm{F}}{\frac{\mathrm{cm}}{\mathrm{cm}^{3}}}} \text {, }
$$

where $A=$ integral under amp vs time curves, ampmin: $\quad F=$ Flow Rate in Kanne Chamber $39.6 \times 10^{3}$ $\mathrm{cm}^{3}$. Numerical values are standard conversion factors. In an 85.5 min test run $6737 \mathrm{~cm}^{3}$ of gas $(31.7$ $\mathrm{cm}^{3}$ of $\mathrm{T}_{2}$ ) was processed. A total of $10.97 \times 10^{-5}$ $\mathrm{cm}^{3}$ of $\mathrm{T}_{2}$ was released 1nto the atmosphere. Thus, the $\mathrm{T}_{2}$ content of the gas was reduced by a factor of 288,900 .

It was observed that the concentration of $\mathrm{T}_{2}$ in the ECS exhaust continued to rise throughout the tests. This gradual rise in concentration is assumed to be caused by the adsorption of tritium wat?r onto the molecular sleve and the assoclated vapor pressure increase. The increase in concentration might be expected to increase over a long period of time to some maximum acceptable level, whereupon the contaminated sleve pellets would be replaced. However, experience with the system should yield more information about the ECS Iong term operating characteristics.

\section{SUMMARY}

An effective method of reducing tritium emisslons into the atmosphere has been demonstrated. Operation of the system is automatically controlled and easily monitored. The molecular sieve containers are designed for easy and safe maintenance. Experience with the long term operating characteristics of the system will probably lead to modifications improving this intital ECS model.

APPENDIX

MATERIALS

The following materlals were used in the construction of the ECS.

\begin{tabular}{|c|c|c|c|c|c|}
\hline $\begin{array}{l}\text { Part } \\
\text { Number }\end{array}$ & $\begin{array}{l}\text { Number } \\
\text { Required }\end{array}$ & Description & & & \\
\hline 1 & 1 & $\begin{array}{l}\text { Holding tank - } 9 \text { liters }-316 \text { stain- } \\
\text { less steelwelded. }\end{array}$ & 8 & 2 & $\begin{array}{l}\text { Molecular Sleve Containers - } 316 \\
\text { Stalnless steelwelded. }\end{array}$ \\
\hline 2 & 1 & $\begin{array}{l}\text { Pressure Switch - "Bristol" Model } \\
506008-05-3 \text {. }\end{array}$ & 9 & 4 & $\begin{array}{l}\text { Solenold Valve - "Skinner" \#V5D } \\
3870 .\end{array}$ \\
\hline 5 & $\begin{array}{l}1 \\
1\end{array}$ & $\begin{array}{l}\text { Rellef Valve - "Circle Seal" 5159B. } \\
\text { Bellows Pump - "Met-Be1" Model MB- }\end{array}$ & 10 & 2 & $\begin{array}{l}\text { Mcrometer Needle Valve - "Hoke" } \\
2335 F 4 Y \text {. }\end{array}$ \\
\hline & & 150. & 11 & 1 & Programmer - "Tenor" 2420. \\
\hline 6 & 1 & $\begin{array}{l}\text { Catalytic Converter - "De-Uxo" } \\
\text { Model D-50-1000. } \\
\text { 4-Way Valve - "Circle Seal" P4- }\end{array}$ & 12 & 2 & $\begin{array}{l}\text { Pressure Regulator "Kenda11" Mod- } \\
\text { el } 30 \text { Cat. No. } 30152 \text {. }\end{array}$ \\
\hline
\end{tabular}
418T. 